\title{
Correction to: Realizing simultaneously enhanced energy and power density full-cell construction using mixed hard carbon/ $\mathrm{Li}_{4} \mathrm{Ti}_{5} \mathrm{O}_{12}$ electrode
}

\author{
Shi-Fei Huang, Yao Lv, Da Tie, Yang Yu, Yu-Feng Zhao* $\mathbb{D}$
}

(C) The Nonferrous Metals Society of China and Springer-Verlag GmbH Germany, part of Springer Nature 2019

Correction to: Rare Met.

https://doi.org/10.1007/s12598-019-01312-4

In the original publication, in Figure 3, part $\mathrm{d}$ has been mistakenly published same as part c. The correct version of Fig. 3 is given in this Correction.

The original article can be found online at https://doi.org/10.1007/ s12598-019-01312-4.

S.-F. Huang, Y. Lv, D. Tie, Y. Yu, Y.-F. Zhao*

State Key Laboratory of Metastable Materials Science and Technology, Key Laboratory of Applied Chemistry, Yanshan University, Qinhuangdao 066004, China

e-mail: yufengzhao@ysu.edu.cn

Y.-F. Zhao

Institute of Sustainable Energy, Shanghai University, Shanghai 200444, China 

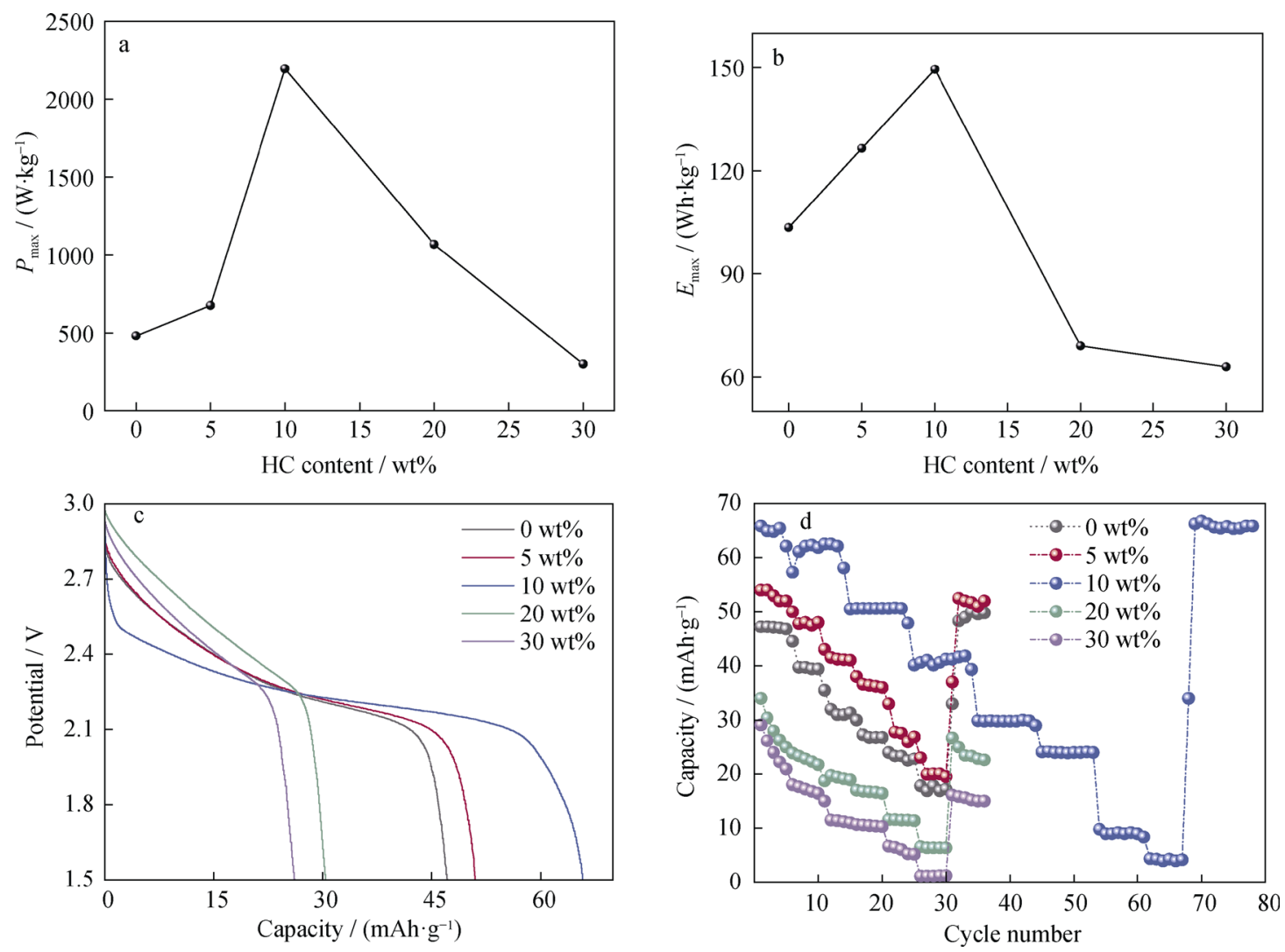

Fig. 3 a Maximum energy density $\left(P_{\max }\right)$ and b maximum power density $\left(E_{\max }\right)$ of NCM111/LTO + HC system; c discharge curves of NCM111/LTO + HC at current density of $0.1 \mathrm{~A} \cdot \mathrm{g}^{-1}$ with operate potential of $1.5-3.0 \mathrm{~V}$; d rate performance of NCM111/LTO $+\mathrm{HC}$ system 